Lexis Vol. XLIV (2) 2020: 619-657

\title{
El papel de las Tradiciones Discursivas en la lingüística histórica mesoamericana. Un ejemplo de los testamentos nahuas
}

\author{
Mauro Alberto Mendoza Posadas \\ Facultad de Filosofía y Letras \\ Universidad Nacional Autónoma de México
}

\section{RESUMEN}

La documentación colonial de lenguas mesoamericanas se encuentra en modelos discursivos de corte europeo. Para entender las relaciones que se establecen entre estas lenguas y los modelos (o Tradiciones Discursivas) en los que aparecen, es provechoso recurrir a los estudios de la romanística. En este artículo, tras hacer un breve repaso de la categoría de Tradiciones Discursivas y sus implicaciones teóricas, aplicamos un análisis centrado en la tradición testamentaria para observar cómo fue que se trasladaron estos documentos al náhuatl del siglo XVI, particularmente en la interfaz sintaxis-pragmática, con el fin de dar cuenta de las diferencias y las similitudes en la Tradición Discursiva en castellano y en náhuatl.

Palabras claves: Tradiciones Discursivas, náhuatl, testamentos coloniales, contacto lingüístico 
The Role of Discursive Traditions in Mesoamerican Historical Linguistics. An Inquiry on Colonial Nahuatl Wills

\section{ABSTRACT}

Almost all colonial documentation of Mesoamerican languages was written on discursive models of European inspiration. In order to understand the relationship between the American languages and these models (or Discursive Traditions), and also to understand the theoretical implications, we made an analysis centered on the testamentary tradition to investigate the way these documents were translated to the sixteenth Century Nahuatl language. We particularly focused on the syntax-pargamatics interphase, so we could find the differences and similarities between the Discursive Tradition in Castilian and Nahuatl.

Keywords: Discursive Traditions, Nahuatl language, Colonial wills, Linguistic contact

\section{Introducción}

A lo largo de los últimos años, ha tenido gran acogida en la romanística el término Tradiciones Discursivas (TTDD) como un elemento fundamental para develar la influencia de modelos de elaboración del discurso en nuestro conocimiento del cambio lingüístico y de la historia de la lengua. Por ejemplo, Kabatek reconoce este papel cuando afirma que "la historia de una lengua no presenta solo variación a nivel de dialectos, sociolectos o estilos, sino que la lengua varía también de acuerdo con las tradiciones de los textos” (2008:10).

Este papel se vuelve aun más importante cuando, como en el caso de algunas lenguas mesoamericanas — sobre todo el náhuatl y el maya, pero también, por ejemplo, en el purépecha y el zapoteco- nuestra documentación más temprana —además de artes y vocabularios - se encuentra en documentos de corte notarial. Peralta, Herrara, Medina, Mentz, Rockell y Sandoval reconocen, asimismo, esta condición cuando afirman que “[...] Había un repertorio de fórmulas para textos legales bien conocidas por los escribanos, oficio al que pronto también ingresaron indígenas o 
mestizos hablantes de lenguas nativas. Son ellos los que elaboraron, precisamente siguiendo los machotes que se les habían enseñado, los documentos que hoy encontramos en los archivos" (2004: 182).

En la medida en que estos documentos funcionan dentro de un rígido mundo discursivo de corte europeo, se vuelve necesario, con el fin de hacer una descripción apropiada de estas lenguas, abordar estos documentos desde el método que se ha desarrollado para este universo de comunidades y lenguas románicas, máxime cuando "la tradición discursiva se vuelve [...] vehículo del contacto lingüístico" (Kabatek 2001: 112).

Por lo tanto, en este artículo nos interesamos, primero, en aclarar, según nuestro entendimiento, el papel de las TTDD dentro del proceso colonial novohispano para, luego, ejemplificar, sobre la base de una serie de documentos testamentarios nahuas del siglo XVI, la importancia que tiene este tipo de estudios dentro de la lingüística mesoamericanista.

\section{Las Tradiciones Discursivas como producto del saber discursivo}

Es necesario recordar que el marco de las TTDD se desprende de la 'lingüística del texto' de Eugenio Coseriu (Coseriu 2007), un proyecto que el rumano había comenzado a realizar desde su etapa en Montevideo con la publicación de "Determinación y entorno. Dos problemas de la lingüística del hablar” (Coseriu 1956, Kabatek 2016). Por eso mismo, es necesario recordar que, para Coseriu, el lenguaje ( $\mathrm{y}$ las lenguas) puede entenderse desde tres perspectivas distintas: en tanto actividad, en tanto saber y en tanto producto. Asimismo, la lingüística del texto de Coseriu también se encuentra segmentada en tres niveles, pues, para él, hay que reconocer que "los textos son hechos individuales, pero no absolutamente singulares, ya que presentan, además, una dimensión universal, que incluye aquellos rasgos de la textualidad, y una dimensión histórica que hace que compartan tradiciones y moldes expresivos" (Loureda 2007: 52). 
Sin embargo, no fue sino hasta el desarrollo del marco de las TTDD que este hecho (la dimensión histórica de los textos) entró en el sistema que se había heredado del propio Coseriu. Basado en la obra de Schlieben-Lange, en la que la autora hace la observación "de que existe una historia de los textos independientemente de la historia de las lenguas y que el estudio histórico de las lenguas la debe tener en cuenta” (Kabatek 2006: 154), Peter Koch llamó la atención sobre un hecho plenamente enunciado en la teoría coseriana: nos enfrentamos a dos diferentes tipos de historicidad que requieren ser reconocidas en la división tripartita original. ${ }^{1}$ Para ello, el autor propone duplicar el nivel histórico tomando en cuenta que los textos requieren ser explicados desde su propia historia, que es independiente de la historia del sistema lingüístico en que se elaboraron, tal como se muestra en la tabla 1 .

Tabla 1. Niveles y dominio de lo lingüístico (Koch 2008: 54)

\begin{tabular}{lll}
\hline Nivel & Dominio & Tipo de reglas \\
\hline Universal & Actividad del hablar & Reglas elocuciones \\
\hline Histórico & Lengua histórica particular & Reglas idiomáticas \\
& Tradición discursiva & Reglas discursivas \\
\hline Actual/individual & Discurso & \\
\hline
\end{tabular}

1 El esquema original que se muestra a continuación lo retomamos de Coseriu, 1992: 80 y ss. En Coseriu, [1976] 1996, también aparece un esquema muy parecido a este. En donde en el original Coseriu escribe "lo que uno expresa (fr.: dicours)" (23), nosotros hemos colocado "discurrir".

\begin{tabular}{|c|c|c|c|}
\hline & 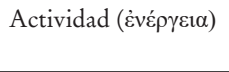 & $\begin{array}{l}\text { Saber } \\
(\delta \dot{v} v \alpha \mu \varsigma)\end{array}$ & $\begin{array}{l}\text { Producto } \\
\text { (Ëprov) }\end{array}$ \\
\hline $\begin{array}{l}\text { Nivel } \\
\text { universal }\end{array}$ & Hablar en general & $\begin{array}{l}\text { Elocutivo, competencia } \\
\text { lingüística general }\end{array}$ & $\begin{array}{l}\text { Totalidad de las } \\
\text { manifestaciones lingüísticas }\end{array}$ \\
\hline $\begin{array}{l}\text { Nivel } \\
\text { histórico }\end{array}$ & Lenguas particulares & $\begin{array}{l}\text { Idiomático, competencia } \\
\text { lingüística particular }\end{array}$ & Lengua particular abstracta \\
\hline $\begin{array}{l}\text { Nivel } \\
\text { individual }\end{array}$ & Discurrir & Expresivo, competencia textual & Texto \\
\hline
\end{tabular}


La duplicación de Peter Koch tiene consecuencias teóricas; la primera de ellas es que se establece que "las tradiciones discursivas, aun constituyendo tradiciones históricas, no se confunden de ningún modo con las lenguas" (2008: 54), por lo que la tradición de las lenguas históricas y la de las TTDD es distinta; esto es a lo que Coseriu se refiere con el adjetivo 'supraidiomático' cuando afirma que "[e]n el caso de los textos supraidiomáticos, entre los que se encuentran, por ejemplo, los géneros literarios, debería resultar evidente que existe una configuración tradicional enteramente independiente de la tradición del hablar según una técnica transmitida históricamente" (Coseriu 2007: 139). Asimismo, en este esquema también se hace énfasis en las particularidades que cobra el saber expresivo con esta nueva división, pues, dice el autor, "el discurso es, en verdad, el lugar de aplicación del saber lingüístico, pero como cada discurso es único y el saber implica la posibilidad de la reproducción, saber y discurso serán incompatibles" (Koch 2008: 54), por lo que, en realidad, existirían dos filtros distintos para la elaboración del discurso [en el sentido de producto de una actividad]: el filtro de la lengua y el filtro de las TTDD. ${ }^{2} \mathrm{La}$ apreciación de Koch, en el que no hay ningún tipo de regla en el nivel individual, busca dejar claro que "no hay que confundir de ningún modo la efectuación actual con el saber virtual que esta 'actualiza'” (2008: 56). Por lo tanto, los saberes pueden ser únicamente, desde su concepción, universales (elocucional) o históricos (idiomático-discursivo), pero no individuales. A su vez, el discurso se entiende en este esquema "únicamente como el nivel de realización de los distintos saberes del hablante" (López Serena 2012: 269). ${ }^{3}$

\footnotetext{
2 También Oesterreicher apunta a esta lectura de un doble filtro en el nivel histórico y de una actividad única en el nivel individual según el esquema original de Coseriu: "Esta diferenciación de tres niveles del lenguaje resulta, en suma, de una determinación sucesiva según la cual la actividad universal del hablar se 'materializa' mediante técnicas lingüísticas y tradiciones discursivas históricas en un discurso o texto individual concreto" (Oesterreicher 2001: 201).

3 Por lo tanto, dentro de este saber expresivo, se encuentran contenidos el saber universal y los dos saberes históricos (el idiomático y el discursivo), "todos ellos necesarios
} 
Nos detendremos brevemente en lo que Coseriu llama 'saber expresivo'. Para el rumano, este saber es el que se pone en marcha en los actos lingüísticos individuales por hablantes específicos y, por lo tanto, "se aplica a tipos de circunstancias y, por ende, de discursos" (2007: 142). A estas circunstancias, Coseriu las denominó 'entornos' y su función "tiene que ver con la determinación de los signos lingüísticos en cada acto comunicativo concreto. Los entornos orientan en la producción y recepción de todo acto lingüístico el contenido de un signo coadyuvando a la constitución del sentido" (Perna 2014: 145). Si retomamos la idea de Koch de que en el nivel individual existe solo actividad, entonces el saber expresivo coseriano, en el que se encuentran el conocimiento de los hablantes para adecuar su habla a las condiciones extralingüísticas, debe ubicarse en un plano distinto, aunque en sí mismo contenga un constituyente histórico; este componente es consecuencia de que los entornos se construyen sociohistóricamente. Debemos reconocer, entonces, que no solo el texto tiene su propia historicidad, sino también la presencia del saber que los produce, por lo que conviene reconocer la existencia de un saber distinto del saber expresivo ${ }^{4}$ relacionado con la estructuración del discurso en términos históricos y no como el saber propio del nivel individual, en

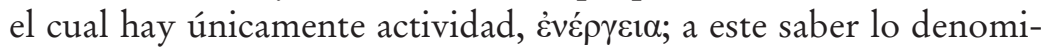
naremos 'saber discursivo'.

A la par de esta distinción, conviene también diferenciar, dentro de este saber discursivo, dos hechos sobre los que Coseriu había llamado la atención. Por una parte, nos encontramos con un saber hablar en tipos de circunstancia y, por la otra, con el saber estructurar discursos. Koch no explicita a cuál de estos se refiere con 'reglas discursivas' ni cómo se relacionan entre sí, aunque

\footnotetext{
para la producción lingüística individual en el marco de una constelación comunicativa determinada" (López Serena 2012: 269).

4 Distinto en la medida en que el saber expresivo debería "comprender, dentro de sí, los saberes tanto elocutivo como idiomático, así como el saber histórico que no es puramente idiomático, sino que se corresponde con el dominio de los modelos textuales o tradiciones discursivas sociohistóricamente determinados” (López Serena 2012: 269).
} 
podríamos pensar que, dentro del saber discursivo, se encuentran presentes ambos. Jacob y Kabatek asumen esto cuando dicen que “a las clásicas 'variedades' del diasistema coseriano se les añade [...], también en la perspectiva histórica, una tipología de constelaciones discursivas, constituidas por las condiciones pragmáticas de producción y de recepción del lenguaje estudiado más las técnicas discursivas y lingüisticas correspondientes" (Jacob y Kabatek 2001: VIII) [las cursivas son nuestras]. ${ }^{5}$

Las condiciones pragmáticas a las que se refieren Jacob y Kabatek se encuentran fuera de lo lingüístico, y su expresión idiomática se encuentra en el saber hablar en tipos de circunstancias, mientras que las técnicas discursivas pertenecen por sí mismas al hecho lingüístico. Las TTDD hacen referencia al saber estructurar discursos, mientras que el producto del saber hablar en tipos de circunstancia, en el nivel histórico, corresponderá la categoría de 'variedad'.

Por lo tanto, si seguimos la tripartición coseriana original, podemos decir que las TTDD son producto ("̌ $\rho \gamma o v)$ de un saber histórico específico —el discursivo-, y de una actividad que es a la vez histórica y que se efectúa en el nivel actual (a la que llamaremos discurrir para distinguirlo de discurso y de texto). ${ }^{6}$

\footnotetext{
5 Araceli López Serena también ha observado este hecho cuando afirma que "a la diferenciación entre lo universal y lo histórico hay que sumar la que se da entre el ámbito de la estructuración de los tipos de discursos (o de la variación genérica o textual), por una parte, y el del hablar en tipos de circunstancias (o variación situacional), por otra, entre las que - a pesar de que existan relaciones claras - me parece indispensable establecer una distinción teórico-metodológica sistemática” (López Serena 2011: 67).

6 'Discurso' y 'texto', por su condición participial, son etiquetas que se acoplan mejor al producto de este nivel histórico. Por su parte, hay que recordar que el propio Coseriu distingue, en ocasiones, entre texto y discurso, mientras que en otras parece tratarlos como sinónimos. Así, por una parte, el discurso es la actividad propia del nivel individual, para la cual preferimos emplear aquí el verbo discurrir, mientras que, por ejemplo, en el esquema en el que basamos el nuestro - que aparece en la imagen 2 - apunta: “plano individual: discurso (texto)" (Coseriu 1992: 80). Antes, en el mismo lugar, dice: "El hablar es siempre individual bajo dos aspectos, a saber: por una parte siempre es un individuo el que lo ejecuta; no es una actividad coral. Cada uno habla por sí y también en los diálogos se asume, alternativamente, el papel de hablante y oyente. Por otra parte, el hablar es individual en el sentido de que siempre tiene lugar en una situación determinada. Para designar esta actividad individual en una situación determinada propongo — por el francés discours - el término «discurso». En alemán, a este plano se le llama
} 
Aprovechando el esquema de Koch, proponemos el esquema que se presenta en la tabla 2 para aclarar lo que hasta ahora hemos mencionado; en él hemos querido salvar la división original coseriana en tres niveles y tres puntos de observación con el propósito de mantener la distinción entre moldes y tipos de circunstancias. Esto quiere decir que hay que mantener, por una parte, una diferencia entro los modelos históricos supraidiomáticos de los modelos idiomáticos (las lenguas históricas), tal y como ya había hecho Koch, a la vez que hay que distinguir ambos como producto de saberes distintos, para así entender el discurrir como la actividad en la que se ponen en práctica estos productos y saberes en distintos tipos de circunstancias; es decir que es en este último nivel donde tienen relevancia las 'condiciones pragmáticas', aunque estas también tienen una configuración histórica.

Todo lo anterior nos lleva a considerar el saber discursivo como un hecho propiamente lingüístico que, de alguna manera, se adecua al mundo en que este discurso se desarrolla. En este sentido, todo discurrir como actividad, en términos pragmáticos, tiene como propósito influir en el mundo en el que ocurre, para lo cual se sirve de modelos que se encuentran contenidos en las TTDD y del saber discursivo del que estas dependen, pues "las tradiciones discursivas funcionan siempre dentro de sociedades en un marco de condicionamientos extralingüísticos constituido, por un lado, por condiciones comunicativas de carácter universal y, por otro lado, por fines de la comunicación históricamente variables" (Oesterreicher 2007: 114).

también «texto», pero en ese caso hay que tener en cuenta que aquí se trata primordialmente de la actividad misma y no del discurso" (Coseriu 1992: 87).

7 Nos parece que Ricardo Renwick entiende también las TTDD en su dimensión histórica según la tripartición coseriana: "El nivel histórico, que concierne a las características de las lenguas históricas entendidas como materializaciones diversas de la facultad general del lenguaje. Este nivel comprende, en primer lugar, el aspecto idiomático, en tanto las lenguas particulares poseen su propia dinámica de evolución y sus propios condicionamientos internos, $y$, en segundo lugar, las tradiciones discursivas, en tanto los productos lingüísticos se configuran también sobre la base del recurso a distintos modelos discursivos establecidos a lo largo del devenir histórico, e independientes del aspecto idiomático" (Renwick 1997: 27) [las cursivas son nuestras]. 
Las TTDD cobran todo su sentido solo dentro de este marco social, ${ }^{8}$ además de que el hecho de que sean sensibles a esta realidad y se muevan, asimismo, dentro de entornos concretos — que, a la vez, tienen que entenderse en una dimensión histórica- ${ }^{9}$ permite que las TTDD tiendan un puente entre lo extralingüístico que se proyecta en la lengua; la historia propia de la TTDD — que se sobrepone a comunidades lingüísticas-; y la historia de una lengua histórica.

\section{Tabla 2. Las Tradiciones Discursivas como producto del nivel histórico}

\begin{tabular}{|c|c|c|c|}
\hline Nivel & Actividad & Saber & Producto \\
\hline Universal & $\begin{array}{l}\text { Hablar en } \\
\text { general }\end{array}$ & $\begin{array}{l}\text { Saber elocucional } \\
\text { (saber hablar en } \\
\text { general) }\end{array}$ & $\begin{array}{l}\text { Totalidad de las } \\
\text { manifestaciones } \\
\text { lingüísticas }\end{array}$ \\
\hline \multirow[t]{2}{*}{ Histórico } & $\begin{array}{l}\text { Hablar una } \\
\text { lengua particular }\end{array}$ & $\begin{array}{l}\text { Saber idiomático (saber } \\
\text { hablar una lengua } \\
\text { particular) }\end{array}$ & Lengua histórica \\
\hline & $\begin{array}{l}\text { Hablar según } \\
\text { modelos } \\
\text { discursivos }\end{array}$ & $\begin{array}{l}\text { Saber discursivo } \\
\text { (saber hablar según } \\
\text { modelos discursivos) }\end{array}$ & $\begin{array}{l}\text { Tradiciones } \\
\text { discursivas }\end{array}$ \\
\hline
\end{tabular}

Actual/individual Discurrir

\footnotetext{
8 "[L]os casos de habla pueden tratarse razonablemente, pues, solo en su «significación» social. Inmediatamente se plantea la pregunta de si estos casos de habla cristalizan en clases de textos determinados, históricos” (Schlieben-Lange 1987: 140).

9 Coseriu está interesado en lo que hay de universal en las constelaciones, dentro de las cuales se encuentra el universo del discurso. Sin embargo, no puede negarse que estos tienen también una dimensión relativa a la construcción social en la que el discurso se efectúa. Si asumimos que estos universos del discurso pueden reducirse a etiquetas como 'literatura', 'mito', 'ciencia', etc., observamos que, efectivamente, todas ellas pertenecen a una clasificación de la organización del discurso que ha desarrollado la cultura occidental, y, aunque pueden extrapolarse a discursos de otras sociedades y otros tiempos, esta siempre es inexacta. A ello hace referencia Shclieben-Lange cuando dice que "en cada sociedad hay varios sistemas de interpretación del mundo coexistentes y en circunstancias también enfrentados y con ello también diversos modos de hablar sobre el mundo" (1987: 135). Más tarde, la misma autora afirmará que "die Diskursuniversen haben selbstverständlich [...] etwas zu tun mit der gesellschaftlichen Organisation” (1983: 140).
} 
Ahora bien, cuando la repetición de elementos se asume como un elemento definitorio de las TTDD, ${ }^{10}$ en realidad se está haciendo hincapié en la cristalización del habla en su uso social, lo que permite identificar un discurso específico dentro de una serie de discursos anteriores y con una constelación discursiva (o entorno) en la que se desarrolla, pues, como dice Garatea: "Gracias a ellas [a las TTDD], un discurso, y de ahí un texto [...] se inscribe en una filiación textual definida por elementos comunes, repetidos, que atañen a los entornos (constelaciones situacionales, mediales o institucionales) y a formas identificables en la superficie del propio texto, como pasajes, fórmulas, estructuras, etcétera" (2004: 407).

De esta manera, las TTDD nos permiten acercarnos a los hechos lingüísticos que ocurren repetidamente en constelaciones específicas; cuando TTDD y constelaciones empatan adecuadamente, las primeras se vuelven praxis y permiten a sus usuarios actuar e incidir en el mundo que los rodea. Esto es evidente, particularmente, en los casos en los que un discurso 'cristalizado' se sostiene en constelaciones discursivas socialmente sancionadas, en las cuales un uso específico es tanto una marca de la constelación a la que pertenece como índice de una TTDD, de tal manera que el "marco concreto de la institución evoca (o lo que es lo mismo, exige) una tradición determinada" (Kabatek 2006: 156). Las constelaciones del discurso son, por lo tanto, una mediación entre el hecho social y el hecho discursivo, pues designan "la combinación de elementos de comportamiento extralingüísticos que entra en un determinado acto de comunicación" (Steger 1972: 60). Ya que estas situaciones no son universales, sino históricas, deben entenderse desde una perspectiva histórica y antropológica. Así pues, para comprender, por ejemplo, por qué existe una relación específica entre participantes de un

\footnotetext{
10 Por ejemplo, la defnición de Kabatek, para quien "el rasgo que define a una TD es, entonces, la relación de un texto en un momento determinado de la historia con otro texto anterior: una relación temporal a través de la repetición de algo. Ese "algo" puede ser la repetición total de texto entero [...], pero también puede ser apenas la repetición parcial o incluso la ausencia total de repetición concreta y únicamente la repetición de una forma textual” (Kabatek 2006: 154).
} 
acto comunicativo, deben establecerse las particularidades de esa situación histórica concreta, la cual subsume al acto comunicativo específico que se está estudiando. De ahí que las constelaciones del discurso (participantes, temas, grado de publicidad del acto, etcétera) estén a su vez condicionadas por la formación social en la que se encuentran.

Por ello, las TTDD son producto de condiciones sociales específicas que se interpretan lingüísticamente y se asimilan en el saber discursivo de quienes las ejecutan. Esta fuerte dependencia se concreta en el hecho de que las TTDD están a su vez sometidas al cambio; “a partir de la variación de las condiciones pragmáticas, [se] promueve la modificación o el cambio de estos modos tradicionales de interacción” (Garatea 2001: 257). Por lo tanto, las transformaciones de las instituciones importadas desde Europa hacia las nuevas colonias implicaron que las TTDD que se elaboraban para el sostenimiento de estas se modificaran; “ante problemáticas o condiciones de producción textual nuevas, se intent[ó] adaptar a las nuevas necesidades político administrativas de la colonia los mecanismos ya conocidos, apelando a estructuras y elementos tomados de tradiciones anteriores” (Guzmán Riverón 2005: 83).

Si las TTDD pueden adecuarse a nuevos contextos pragmáticos y a nuevas lenguas históricas — pues queda claro que son independientes de las últimas y están determinadas por los primeros- entonces, en una situación en la que se desarrollaron TTDD europeas en lenguas indígenas, su presencia es una manifestación más de la condición colonial en la que se desarrollaron. Paoli ha llamado la atención sobre esta adecuación de tipos de discurso a nuevas situaciones a través del proceso de traducción; para él, la traducción puede establecerse entre formaciones sociales idénticas, "ante relaciones sociales similares, o estructuralmente iguales, se posibilitan concepciones de la realidad que tienden a identificarse y a ser traducibles a los diversos lenguajes derivados de formaciones históricas similares” (Paoli 1989: 65); por lo tanto, el desarrollo de TTDD europeas en lenguas indígenas implica que la formación social 
prehispánica se subsumió en la europea, que es la que modela el discurso y la acción de la primera, ya que

todo aparato de hegemonía que desarrolla sistemas de dirección y dominio de una sociedad, tiende a definir y redefinir constantemente, a través de su lenguaje y de su acción, sus finalidades sociales, su sentido, sus formas de interpretar la realidad. Y tiende a traducir esas formas y ese sentido a los lenguajes de todos los pueblos o las clases a que se extiende, o quiere llegar a extender su hegemonía (Paoli 1989: 66).

En tanto que las TTDD son producto de un saber discursivo específico, la confección de estas en sociedades para las cuales eran ajenas implica la imposición y la aceptación de las condiciones específicas sobre las cuales se desarrolla este saber, además de la importación de las diferentes constelaciones que los acompañan. Por lo tanto, las TTDD enmarcan las posibilidades de la praxis discursiva de las comunidades idiomáticas que las emplean. Es así que, tras la instalación de las instituciones castellanas a los nuevos territorios, se trasladaron también las TTDD que se empleaban dentro de ellas.

De ahí que este proceso de traslado pusiera en contacto el saber discursivo detrás de la elaboración de TTDD determinadas con un saber discursivo propio de las comunidades mesoamericanas, cuya existencia apenas comenzamos a prefigurar, pues, aunque existen algunas evidencias de ciertas formas de discurso, solo podemos llegar a observar algunas características de este saber discursivo de manera deductiva; ${ }^{11}$ en este proceso de deducción, el conocimiento de las TTDD europeas se vuelve fundamental, ya que en ellas se manifiestan las particularidades del saber discursivo castellano.

Este proceso también es fundamental para el análisis de la variación diafásica, a la cual suele llamarse 'variedad', pues si la variación de carácter universal se manifiesta en la variación diafásica de la

\footnotetext{
11 Sobre todo, y gracias al desciframiento de la escritura maya del periodo clásico mesoamericano, hemos reconocido algunas estrategias discursivas que se encontraban presentes ya en la escritura epigráfica. Véase Wichmann 2004; para un estudio de paralelismos en náhuatl, véase Bright 1990.
} 
arquitectura coseriana, entonces en esta variación encontraremos variedades lingüísticas relacionadas con contextos específicos de uso. Distinguir, a la vez, entre variedades diafásicas y TTDD como tipos de variación dentro del nivel histórico de lo lingüístico nos permite enfocar el estudio en dos perspectivas complementarias. En la primera, considerando que las TTDD son modelos para la organización discursiva, podemos diferenciar entre los elementos, idiomáticos o no, que deben presentarse para que ese discurso pueda pertenecer a dicha tradición. En la segunda, debido a la variación diafásica es un hecho meramente idiomático, describir una de estas variedades en términos lingüísticos permite dar cuenta de la manera en que una TD ha sido trasladada de una lengua a otra en ciertas condiciones pragmáticas específicas, pues "desde la perspectiva del registro, el contenido en términos de estructuras lingüísticas y discursivas se analiza en relación a los contextos de uso y a los productores, con lo cual se integra la dimensión pragmática” (Montes de Oca 2017: 148).

2. Los testamentos nahuas del siglo XVI desde la perspectiva de las TTDD

2.1. Algunos aspectos históricos del testamento en la Nueva España

Las necesidades administrativas obligaron a desarrollar las técnicas lingüísticas apropiadas para que el náhuatl pudiera desempeñar un papel funcional dentro de la burocracia colonial; por ello, como afirma Hidalgo, "the transliteration of Nahuatl and other languages into Romanaized written was not the result of a frivolous undertakings but the outcome of meticulous scholarship" (2006: 59). El desarrollo de una variante de la lengua especializada, tanto en los ámbitos religiosos como administrativos es, por lo tanto, parte de un mismo proyecto de colonización:

On the face of it, speech and communicative practices are inalienable parts of policía in everyday social life, just as they are the necessary medium in which to persuade would-be converts of 
the message of Christianity, and also the medium in which much prayer and religious practice takes place. But the tie to language runs deeper still, since the indigenous languages were the objects, and not only the instruments, of reducción (Hanks 2010: 4).

El testamento es un claro ejemplo de este ejercicio lingüístico. Para el testamento, no son los componentes de la lengua dentro del mismo, ni las relaciones que establecen entre sí, los que establecen el tipo textual, sino que son las necesidades pragmáticas - las determinaciones coserianas - las que se imponen en el modelo discursivo que lo componen; en este marco se encuentran las normas jurídicas de la época y la institución de la propiedad y la herencia. En términos jurídicos, el testar es el "[acto en que] una persona establece heredero y dispone sus bienes para cuando fallezca” (Martir Alario 2011: 152), en tanto que un testamento es "el documento en que se consigna y consta la voluntad” (Martínez 1996: LXXI). El marco jurídico occidental en el que este acto tiene sentido es bastante antiguo y se remonta directamente al mundo romano, que atraviesa una revitalización durante el reinado gótico en la península ibérica y una posterior codificación en el Fuero juzgo, el cual sufrió modificaciones en la época alfonsí y en las Leyes de Toro ya en el siglo XVI. ${ }^{12}$

El testamento era también, en la época en la que nos encontramos, un acto religioso; así consta en la definición que de este tipo textual hace Yrolo en La política de escrituras, primer manual notarial novohispano:

El testamento es la última voluntad del hombre y una protestación de justicia con que se apareja a dar a cada uno lo que es suyo, cada

\footnotetext{
12 "Fue en el siglo XIII cuando se definió el contenido y la forma de la escritura notarial moderna, y a partir de entonces se estableció una continuidad que dura prácticamente hasta nuestros días; ya que si bien los formulismos se han ido modificando a través de los siglos para adaptarse a las diferentes condiciones históricas de la sociedad $-\mathrm{y}$ hoy, por ejemplo, ya no se exige que una mujer cuente con la licencia de su marido para negociar con sus propios bienes, ni tampoco es necesario jurar por Dios y por nuestra ánima para garantizar el cumplimiento o la verdad de algo; todavía es posible reconocer en las escrituras contemporáneas las características básicas establecidas en el siglo XIII" (Mijares Ramírez 1997: 78).
} 
y cuando que el tiempo determinado por Dios fuere cumplido y cúmplese cuando llega la muerte. La cual es un apartamiento del cuerpo y del alma y una privación con que se acaba la vida mortal $y$, al que toma en buen estado, no es otra cosa sino un remate de los trabajos del cuerpo y un cumplimiento de su destierro, y un dejo de carga pesada, y una salida de la cárcel y entrada en la Gloria (Yrolo [1605] 1996: 170).

La prolija definición del significado de la muerte en el mundo católico, posterior a la contrarreforma, no es accidental; el testamento se convirtió en uno de los actos básicos de protestación de fe $\mathrm{y}$, de hecho, la posibilidad de testar y, por lo tanto, heredar, estaba condicionada a esta declaración: todo buen cristiano debía procurar no morir intestado. En comunidades como la madrileña "the church could deny Christian burial to anyone dying intestate: the church was making it clear that without a will there could be no salvation" (Cline 1998: 16). ${ }^{13}$ Ciertamente, testar era también un acto religioso en las comunidades indígenas que se encontraban bajo adoctrinamiento; esto queda manifiesto en el hecho de que el domingo $20 \mathrm{de}$ mayo de 1565, se impuso, en misa, la elaboración de un testamento para la transmisión de herencia de tierras entre los indígenas. El extracto, perteneciente a Los anales de Juan Bautista, dice:

Hoy domingo 20 de mayo de 1565 años, entonces se pregonó lo del testamento, lo que dejan los que se mueren, lo que dejan en herencia. Y se pregonó en razón de que no se verifica lo que dejan dispuesto los difuntos, si tal vez algo dedican al templo, tal vez para ayuda de su ánima y no se cumple. Y por eso el padre investiga, todo se verá lo que se tiene en la Audiencia. Y el enfermo al hacer el testamento, a dos o cuatro [personas] les dejará encargado que ayuden a su ánima. Y una vez hecho el testamento, luego lo mostrarán a los padres para que se cumpla lo que dejó dispuesto (Reyes 2001: 318-319).

\footnotetext{
$13 \mathrm{Y}$, de hecho, esto también es cierto para cualquier otro acto jurídico: "El matiz religioso de los actos jurídicos se manifiesta en las escrituras mediante la inclusión obligatoria de invocaciones que sitúan a Dios como principal testigo, y juramentos que garantizan el cumplimiento de las obligaciones” (Mijares Ramírez 1997: 28).
} 
Como vemos, al menos en términos ideológicos, es importante el testamento para la salvación del alma. Los padres estaban tan interesados en la escritura de estos testamentos que, una semana después, según estos anales, se leyó un modelo testamentario en misa elaborado por fray Alonso de Molina:

Domingo 27 de mayo de 1565 años, entonces se pregonó en el templo, se dio lectura en el libro de que así se hará el testamento, cómo se pondrá el encabezado, con lo que empieza a existir el formulario de la palabra en que estudiarán los escribanos; lo dispuso nuestro padre fray Alonso de Molina (Reyes 2001: 318-319).

Según Luis Reyes, lo que se leyó en esta misa debió ser la primera edición del Confesionario mayor en lengua mexicana y castellana, que se imprimió también en mayo de 1565 (2001: 319). Sin embargo, sabemos de la presencia del modelo notarial hasta la segunda edición de esta obra, impresa cuatro años después, en 1569.

Molina, el autor de este Confesionario, fue uno de los más grandes intelectuales franciscanos de su época. Aunque nacido en Extremadura, llegó a tierras novohispanas aún niño y aprendió en esos años la lengua nahua. Su rápido ingreso a la orden franciscana lo colocó en medio del proyecto religioso empeñado en el destierro de las creencias prehispánicas que aún eran practicadas, por lo que dedicó su maestría en la lengua a la tarea evangélica, ya escribiendo documentos doctrinales, ya elaborando materiales lingüísticos para que otros frailes aprendieran la lengua.

El conocimiento de la lengua que poseía Molina le permitió desarrollar documentos que emplean tanto la variante que Mentz (2008) llama náhuatl de escribanía y la que la misma autora denomina náhuatl de doctrina; su modelo testamentario está conformado por una serie de recomendaciones a escribanos basadas en las disposiciones legales de la época; por ejemplo, se les amonesta que verifiquen la salud mental del testador, así como que se cercioren de que este hace el testamento por su propia voluntad. Además, presenta diversos escenarios con la presencia de un número determinado de testigos a la hora en que el enfermo dicta el testamento 
y quiénes son sujetos apropiados para desempeñar la institución de herencia. Posteriormente, el modelo presenta un ejemplo testamentario a la manera de los formularios castellanos. Este conocimiento de la legislación y de la tradición de elaborar modelos notariales para la escritura de documentos legales nos indica la penetración del mundo jurídico en la Nueva España y su conocimiento por parte de los catequistas de las comunidades indígenas.

A la vez, el autor es consciente de que el acto de testar es parte del mundo religioso de la época, en el cual la muerte se encuentra ritualizada. De esto da cuenta la colocación del modelo notarial dentro de una obra cuya función principal es la de corroborar si la doctrina está siendo bien enseñada y seguida por los creyentes. Además, para Molina, el acto religioso se encuentra por encima del de herencia, tal como vemos en las instrucciones a los escribanos:

este testamento que agora queréis hazer es para remedio de vuestra alma y para que no se maltrate ni desperdicie vuestra hazienda: y por tanto os conviene que lo hagáis como es justo pues con esto os disponéis para vuestra muerte (Molina [1569] 1984: 59r).

Ahora bien, es necesario decir que la aparición de este modelo es bastante posterior a la escritura de testamentos en dichas comunidades, que puede remontarse a 1531 . No sabemos si existía una versión anterior del machote, aunque según Lockhart (1999: 653 y ss.) es posible que desde antes existiera un modelo del propio autor que circulara por escribanías franciscanas. A este respecto es importante mencionar que, en otro lugar (Mendoza 2018), hemos hecho constar que la influencia del modelo de Molina en los testamentos revisados para esta investigación es bastante reducida; por ejemplo, respecto a la intitulación, que es la fórmula en la que se enuncia quién es el que está testando, el modelo de Molina reconoce la necesidad de indicar la parroquia de adscripción del testador, pero en ningún otro caso se hace esta indicación. A nivel léxico, además, podemos observar la presencia de más préstamos del castellano en los documentos analizados que en el modelo de Molina. 
La elaboración del modelo de Molina, así como la proliferación de esta TD en las comunidades indígenas, ha llevado a preguntarse a varios investigadores si existía una tradición previa para establecer la herencia dentro de las comunidades prehispánicas; por ejemplo, Lockhart (1999) y Cline (1986) suponen que debió haber existido, pero no presentan evidencia de su presencia en las sociedades indígenas prehispánicas. Así, por ejemplo, Lockhart apunta que

no se ha conservado ningún ejemplo de lenguaje testamentario indígena; en realidad, ni siquiera es seguro que antes de la conquista existiera una forma estrechamente parecida al testamento europeo. Sin embargo, el sorprendente éxito del género testamentario en el mundo nahua después de la conquista sugiere una convergencia con algún antecedente significativo indígena (Lockhart 1999: 521).

Cline parece menos dubitativa al respecto: "the Aztec did have a tradition of performing important transactions, such as the sale of the land and slaves, in public. Perhaps before the conquest Aztecs publicly bequeathed property through oral declarations" (1986: 16). Las inferencias hechas por estos autores nos parecen poco convincentes. Por lo tanto, y ante la inexistencia de evidencia directa, preferimos asumir que la tradición testamentaria llegó a la Nueva España con la Conquista; esto no tiene ninguna consecuencia en nuestro análisis, pues este parte de los modelos europeos y su traducción al náhuatl.

Retomando el formulario de Molina, cabe apuntar que, como es de esperarse, no fue realizado ex nibilo por el ingenio del autor, sino que se corresponde con la amplia escritura testamentaria castellana que, como hemos apuntado, se encontraba normada por el derecho castellano alfonsí y sus posteriores modificaciones. Decir, empero, que las formas notariales alfonsíes fueron las que se tradujeron directamente al náhuatl sería inexacto, pues en la época de Molina existían, a su vez, modelos notariales; específicamente, Rojas, Rea y Medina (1999: 11-22) identifican que el modelo seguido por Molina es el que se encuentra en Suma del estilo de escribanos de Lorenzo de Niebla, publicado en 1565, aunque con una probable primera edición de 1564. Seguramente, resultará problemático encontrar una única fuente de la cual se nutriera Molina para la elaboración de 
su testamento, y si se asume que es el modelo de Niebla es porque se tienen indicios de su presencia en las notarías novohispanas (véase Rojas 1999: 11-19). Parece probable atribuir el modelo de Molina a toda la serie de modelos notariales anteriores y al reconocimiento de las fórmulas básicas de estos.

\subsection{Los verbos de transferencia en los testamentos castellanos y nahuas}

Queremos ahora centrarnos en uno de los eventos comunicativos más importantes de las disposiciones testamentarias: la transferencia de bienes. Lingüísticamente, la transferencia es un evento en el que "an agent transfers a theme from his/her own custody to that of a recipient” (Andrews 2007: 158). En términos sintácticos, estos son verbos que llamamos ditransitivos, una subclase de los verbos transitivos que se caracterizan por presentar "two objects, or at least two nonsubject arguments” (Dryer 2007: 253). Los eventos de transferencia, entonces, aparecerán en los documentos descritos por verbos parecidos a 'dar' en español y variarán léxica y sintácticamente según la relación que establezcan con los argumentos A, T y R; es decir, su variación se corresponderá con la forma en que se pone en perspectiva una parte del evento básico de transferencia.

Para Tuggy (1997), los eventos de transferencia, translingüísticamente, tienen la posibilidad de estar alineados o con los eventos de manipulación o con los de interacción humana; esto significa que el segundo elemento codificado en el verbo, además de quien transfiere, puede ser el tema o el receptor según el comportamiento de la lengua. El náhuatl, a diferencia del español, se comporta como una lengua donde el evento de transferencia es cercano a los eventos de interacción humana, de allí que el tipo de relaciones sintácticas que se establecen en la base verbal son distintos; esto es lo que Dryer llama 'objeto primario', una instancia del objeto en la que el tema de una cláusula transitiva tiene el mismo comportamiento sintáctico que el recipiente de una ditransitiva, lo cual se encuentra motivado por razones pragmáticas: "In ditransitive clauses, the IO tends to be more 'topical' than the DO, since the IO is generally human and 
definite, and often 1st or 2nd person; the DO is generally non-human and indefinite, and almost invariably 3rd person" (1986: 845). En el náhuatl sucede así en las relaciones sintácticas marcadas en verbos como maca, 'dar', pues, en este verbo, el recipiente es el que aparece marcado en la palabra verbal en el lugar del objeto, en tanto que el tema se encuentra fuera de esta, como si fuera un oblicuo.

Los ítems léxicos empleados para describir los eventos de transferencia en los testamentos que hemos analizado ${ }^{14}$ son maca, 'dar', cui, 'tomar' y cabua, 'dejar'. Estos tres ítems tienen un total de 126 ocurrencias en los 8 documentos revisados; maca es el principal, con 76 apariciones. Ejemplos de este verbo en documentos se puede observar en (1). Son característicos de estos elementos que aparezcan bajo procesos de diátesis, esto es, que reducen o aumentan su valencia a través de formas aplicativas y pasivas, así como de formas impersonales; este último procedimiento es el más usual en la documentación (2). En los ejemplos se marcará en negritas el ítem verbal que indica la transferencia.

(1) Verbos de transferencia en náhuatl

1a. Modelo de Molina ${ }^{15}$

chicome pesos ma qui $<\mathbf{m}>$ maca yn $[\ldots]$ nopilhuan

chicome pesos ma ø-quim-maca yn no-pil-huan siete $\quad$ pesos OPT 3sUJ-3OBJ.PL-dar DET 1POS-hijo-POS.PL 'siete pesos, que se les dé a mis hijos'

1b. Testamento de Ana de Guzmán

in in inmac niccahua in doña Cathali-/ ${ }^{19}$ na ihuan in don Martin Ceron in in in-ma-c in doña Catalina ihuan in DET DET 3POS.PL-mano-LOC DET doña Cartalina CONJ DET don Martín Cerón don Martín Cerón 'esas [unas tierras] las dejo en las manos de doña Catalina y de Martín Cerón'

14 Los documentos que empleamos para este artículo fueron 8 testamentos nahuas escritos en el siglo XVI y que hemos obtenido del Archivo General de la Nación (México). Los ejemplos provienen de la edición crítica de estos documentos que presentamos en Mendoza, 2018.

15 La versión de Molina la retomamos de la edición facsimilar del Confesionario. 
1c. Testamento de Felipe de Santa María

ma niman quimocuili/34 ${ }^{34}$ tlalli iuan cali in teopixqui

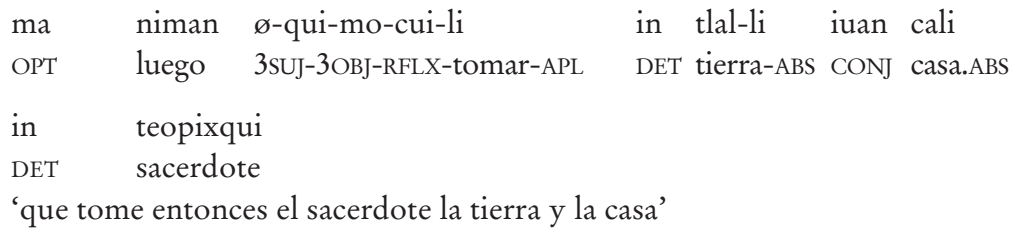

(2) Verbos de transferencia en forma impersonal en náhuatl

2a. Testamento de Francisco Hernández

auh in caltepiton in Tlalnepantla icac moma- $/{ }^{10}$ catiuh in nonamic

$\begin{array}{lllll}\text { auh in } \quad \text { caltepiton } & \text { in } & \text { Tlalnepantla } & \text { ø-icac } \\ \text { CONJ DET } & \text { casa.DIM } & \text { DET } & \text { Tlalnepantla.LOC } & \text { 3sUJ-estar.de.pie } \\ \text { ø-mo-ma-cauh-tiuh } & \text { in } & \text { no-namic } & \\ \text { 3sUJ-RFLX-mano-dejar-LIG-ir } & \text { DET } & \text { 1POS-esposo } \\ \text { 'y la casita que está en Tlalnepantla se irá a dejar a las manos de mi esposa' }\end{array}$

2b. Testamento de Ana Teacapan

mocahuaz in teopan huetzintli ce peso

$\varnothing$-mo-cahua-z in teopan huetzintli ce peso

3sUJ-RFLX-dejar-FUT DET iglesia.LOC ofrenda.ABS un peso

'se dejará a la iglesia un peso de ofrenda'

2c. Testamento de Martín Jacobo

mocuiz chicompohualli pesos

$\begin{array}{lll}\varnothing \text {-mo-cui-z } & \text { chicompohualli } & \text { pesos } \\ \text { 3sUJ-RFLX-tomar-FUT } & 140 & \text { pesos } \\ \text { 'se tomará 140 pesos' } & & \end{array}$

Es necesario contrastar estos ítems con los que aparecen en documentos castellanos. Para lograr esto, hemos analizado seis modelos notariales del siglo XVI elaborados en España y dos testamentos: uno español y otro novohispano. ${ }^{16}$ En estos documentos hemos

16 Estos formularios son, en orden cronológico, el “Testamento" en la obra Summa de notas copiosas, muy sustanciales y compendiosas, según el uso y estilo que agora se usa en estos reinos, impreso en Burgos por el librero Juan de Medina en 1538; el denominado "Cabeça de testamento más breve" que aparece en Recopilación de notas de escripturas 
observado que los ítems léxicos que se emplean en este caso son 'heredar', ‘dejar por heredero' y 'mandar'; 'dar' se emplea únicamente en la fórmula diplomática 'dar poder cumplido', por lo que no lo tendremos aquí en consideración. Cabe decir que la cantidad de verbos de transferencia es mucho menor en el castellano que en el náhuatl; esto se debe a una condición particular de las formas de herencia europea en la cual se establecía un heredero único, llamado jurídicamente 'universal heredero', mientras que en los documentos nahuas se emplea uno de esos verbos cada vez que se habla de diferentes herederos; en los ejemplos de (3) se pueden observar ejemplos de los modelos castellanos y de un testamento. En contraposición con los documentos nahuas, en los casos en español, no encontramos ningún tipo de cambio en las relaciones sintácticas de los verbos. Como veremos más adelante, esto es muy importante para la distinción entre los documentos castellanos y los nahuas, por lo que en la siguiente sección establecemos una comparación entre los dos tipos de documentos en las características relevantes para esta investigación. ${ }^{17}$

públicas, útiles y muy provechosas, por las quales qualquier escrivano podrá ordenar qualesquier escripturas que ante él se otorgaren, de las que se acostumbran en todos estos reynos del escribano Roque de Huerta, publicado en Salamanca en 1551; el "Testamento" que aparece en la segunda edición de Escripturas y orden de partición y de residencia, y judicial, civil y criminal con una instrucción particular a los escrivanos del Reyno y Segunda y tercera parte del escribano Diego de Ribera de 1596 publicada en Toledo, aunque contó con una primera edición de 1563 que tuvo numerosas reimpresiones y que fue harto conocida en el medio; la "Cabeça de testamento" que aparece en la Summa del estilo de escrivanos $y$ de herencias, y particiones y escripturas y avisos de Inezes del escribano público Lorenzo de Niebla, que se publicó en Sevilla en 1565, apenas cuatro años antes que el de Molina y que, se sospecha, pudo ser su modelo, pues se sabe de su presencia en Nueva España; finalmente, el “Testamento ordinario", presente en la obra de Bartolomé de Carvajal Institución y memorial para escrivanos y juezes executores, assí en los criminal como cevil y escripturas públicas, versión corregida e impresa en 1585 en Granada, donde fue escribano real. La edición de estos documentos la hemos tomado de Martir Alario (2011). Además de estos, hemos incluido un testamento castellano perteneciente a María Gómez de Engómez de San Sebastián, en el actual País Vasco, que fue escrito en 1537 y cuya edición retomamos de la obra Documentos públicos y privados. Textos para la historia del español colonial I (Arias 2014).

17 Una revisión completa de las características de los documentos castellanos empleados se encuentra en Mendoza (2018). 
(3) Verbos de transferencia en los documentos castellanos

3a. Modelo de Huerta

e quiero que la dicha yglesia aya y herede todos los dichos mis bienes

3b. Modelo de Carvajal

Tomen de mis bienes lo que bastaren

3c. Testamento de María Espinosa

mando a Úrsula, mi criada, dozientos pesos de oro común por el tiempo que me sirvió

2.3. Un análisis del saber discursivo sobre los verbos de transferencia en los documentos testamentarios

Habiendo analizado estas características verbales de la variedad empleada en los testamentos, ¿qué nos dicen de la TD en lengua nahua y en que difieren ambas tradiciones respecto de la descripción de los eventos de transferencia? Sobre la base de la definición de Foley (2007) de perspectiva, hay una diferenciación importante en la forma en que se presentaban estos eventos, ya que los testamentos castellanos tienen preferencia por describir el evento desde la perspectiva del participante $\mathrm{R}$, en tanto que se codifica como el sujeto del verbo 'heredar', mientras que los testamentos nahuas tienen una preferencia por hacerlo con la perspectiva del donante, el participante A del evento de transferencia, que es el sujeto del verbo maca. A ello, hay que añadir que, en el náhuatl, existe un amplio repertorio de operaciones que permiten modificar las relaciones sintácticas que establecen los verbos con sus argumentos y, por lo tanto, modificar la forma en que se establece esta perspectiva en la descripción del evento de transferencia. Gracias a este tipo de procesos, en náhuatl se puede establecer la descripción desde la perspectiva de T, el objeto que se transfiere, con la forma posicionalimpersonal de cabua, fenómeno que jamás ocurre en castellano, a pesar de que son procesos que la lengua disponía en su sintaxis. Por el contrario, en el castellano, se prefiere el cambio del ítem léxico en caso de que esta perspectiva sea distinta; además, dada la poca presencia de verbos de transferencia, estos cambios no suelen ocurrir en la elaboración de los documentos testamentarios castellanos. 
Estos dos hechos -el cambio de perspectiva y los procesos de cambio de valencia- están relacionados entre sí; por un lado, el empleo de los cambios de voz permite reordenar las relaciones sintácticas, gracias a lo cual se establece un nuevo participante como sujeto de esta oración y se elimina a otros de las relaciones sintácticas nucleares. Esto pone en perspectiva a uno de los participantes que no tenía ese estatus, sobre todo en los procesos de disminución de valencia, pues otorgan las prerrogativas del sujeto a un participante que de otra manera no podría tenerlas. A su vez, estos cambios deben entenderse dentro del contexto en el que ocurren, es decir, a nivel discursivo. Por ello, debemos acercarnos al trabajo de Du Bois (1987) en el que desarrolló el análisis de lo que en español se conoce como Estructura Argumenta Preferida (PAS en inglés).

En su análisis seminal, Du Bois se acercó a una serie de narraciones en el sacapulteco, una lengua de la familia maya hablada en Guatemala; a través de la ocurrencia de las FN de los participantes $\mathrm{S}$ en los verbos intransitivos, y $\mathrm{A}$ y $\mathrm{O}$ en los transitivos ${ }^{18}$, concluyó que la aparición de nueva información suele ocurrir en los participantes $\mathrm{S}$ y $\mathrm{O}$, con lo que A se reserva para hablar de información dada $;^{19}$ esto es consecuencia de que la información nueva es, cognitivamente, más difícil de procesar, de tal forma que suele restringirse, por lo menos en el habla espontánea, a un solo elemento nuevo por oración. La calidad de la información — si es dada o nueva - la define el autor de la siguiente forma: las referencias dadas (given en el original) son aquellas que refieren "to an entity mentioned previously; or if the referent was notably present in the context of situation, as in the case of the speaker and andressee"

\footnotetext{
18 Estas etiquetas para los distintos participantes del verbo las retomó de Givòn.

19 Entendemos por información nueva elementos que aparecen por primera vez en el discurso y que no pueden presuponerse o inferirse a partir de lo que se ha mencionado con anterioridad. La información dada es información que puede recuperarse en el discurso o inferirse del universo del discurso en el que tiene lugar cada uno de los textos. Evidentemente, el estatus de esta información tiene repercusiones en la manera en la que se estructura cada uno de los eventos de transferencia que se describen en el testamento. De igual forma, esto tiene repercusiones sintácticas, que es lo que mostraremos a continuación.
} 
(Du Bois 1987: 816); esta se contrapone a la información nueva (new), que es aquella que hace referencia "to a referent that had not been mentioned previously” (Du Bois 1987: 816). Las restricciones que plantea Du Bois como parte de la PAs se pueden observar en la figura 3.

Figura 3. Restricciones de la $\mathrm{PAS}^{20}$

\begin{tabular}{lll}
\hline & Gramática & Pragmática \\
\hline Cantidad & $\begin{array}{l}\text { Evitar más de un argumento nuclear } \\
\text { léxico }\end{array}$ & $\begin{array}{l}\text { Evitar más de un nuevo } \\
\text { argumento nuclear }\end{array}$ \\
\hline Rol & Evitar A léxico & Evitar A nuevo \\
\hline
\end{tabular}

$\mathrm{Al}$ asumir estos hechos como una tendencia universal de organizar el discurso, a la que, de alguna forma u otra, tanto el náhuatl como el castellano obedecen, cabría preguntarse si en la construcción del discurso testamentario se respetan estas formas y si, en tanto que ambas lenguas describen en esencia el mismo evento, la forma de estructurar la información es similar en ambas, o bien el hecho de tener tantas diferencias léxicas y de procesos sintácticas entre ambas hace que este discurso se organice de manera distinta en una y en otra.

Empecemos nuestro análisis por el castellano. Los dos testamentos analizados pueden ilustrar la forma en que el castellano organizaba esta información en el discurso. En el testamento de María Gómez, de 1537, ubicamos únicamente un ítem verbal de transferencia, el verbo 'mandar'. Aunque el verbo aparece léxicamente en una sola ocasión, se encuentra elidido durante tres periodos distintos. Como es de esperarse, el A, que es la testadora, no aparece realizado léxicamente, sino a través de procesos morfosintácticos, en este caso, la concordancia en el verbo que asegura su estatus como sujeto. Cabe mencionar que esta es información dada que ha sido establecida en la intitulación del testamento a través de un predicado no verbal, por lo que podemos decir que su primera

20 Versión original en Du Bois (2013: 32). 
aparición se trata de un $\mathrm{S}$ que posteriormente puede ser obviado. Los argumentos que deben entenderse como $\mathrm{R}$ se encuentran realizados o bien como objetos indirectos o bien como benefactivos oblicuos introducidos por la preposición 'para'. En ninguno de los dos casos hay presencia de reduplicación a través de la presencia del clítico dativo. En todos los casos, se desarrolla léxicamente el T del evento de transferencia; es decir, el discurso en este testamento viola la tendencia de evitar más de un nuevo argumento nuclear a la vez, tal y como observamos en (4). El caso del testamento de María de Espinosa, de 1572, es bastante similar, aunque en este segundo aparecen en más ocasiones realizaciones léxicas del verbo de transferencia, que también es 'mandar'. En la gran mayoría de los casos, la información se organiza como en el primer evento de transferencia del testamento arriba mencionado; es decir, el A aparece codificado a través de la concordancia con el verbo - pues ya no es información nueva- y se realizan léxicamente tanto el $\mathrm{R}$ como el $\mathrm{T}$, con lo que también se viola la restricción de $\mathrm{Du}$ Bois de introducir solo un nuevo argumento, lo que se observa en (5).

(4) Testamento de María Gómez

Item $\varnothing$ mando \{para la fábrica de la dicha iglesia de Señora santa María\}, A OBL.BEN

un real de plata $\mathrm{T}$

y a la iglesia del Señor sant Vicente $\varnothing$ medio real de plata; OI A.vBO.

$\mathrm{T}$

(5) Testamento de María de Espinosa

Item $\varnothing$ mando a Úrsula, mi criada, dozientos pesos de oro común A.VBO $\mathrm{R}$

Item $\varnothing$ mando a Francisca, mi criada, dozientos pesos de oro común A.VBO $\mathrm{R}$ $\mathrm{T}$

Como podemos ver, en los testamentos castellanos se tiende a violar la PAs. Esto se debe a que tanto el $\mathrm{T}$ como el $\mathrm{R}$ suelen ser información nueva, y la única información dada es la del A, que se 
establece con claridad en la cláusula de intitulación y que, a lo largo de los documentos, suele aparecer en primera persona.

Cabe preguntarse ahora cómo funciona este tipo de organización discursiva en la documentación nahua. Para poder dar una respuesta, habrá primero que hablar del orden de constituyentes en la lengua. Generalmente, suele asumirse que el orden 'neutral' de constituyentes es VSO (véase Launey 1992), pero que puede guardar alguna libertad en su colocación; sin embargo, y como el propio Launey reconoce, "classer le nahuatl comme langue à ordre des mots libres, ou comme langue à prééminence $\mathrm{VSO}$, constitue une analyse totalement superficielle" (Launey 1986: 1487). El arreglo de los elementos suele responder a una 'jerarquía' sensible al tamaño de los constituyentes (simple>compleja), a la presencia de determinantes $(\varnothing>$ in), a la función (sujeto $>$ objeto; objeto primario $>$ objeto secundario), al argumento nuclear sobre el oblicuo y a la forma nominal sobre la verbal (complemento nominal>complemento verbal). También es posible encontrar alguno de ellos en posición preverbal; este fenómeno tiene que entenderse como un proceso que Launey llama tematización: "In cibuatl cochi podría ser traducido por: «la mujer, ella duerme»" (Launey 1992: 22). Es necesario distinguir dos tipos de movimiento a la periferia izquierda: los primeros de ellos Launey los llama 'constructions compactes' y se caracterizan por carecer de determinante antepuesto al elemento desplazado. A la posición compacta Launey le atribuye, además de otros efectos, el de ser el portador de nueva información (Launey 1986: 1500-1514). A ella se contrapone la posición temática, que se caracteriza por estar antecedida del determinante in; esta posición temática, a diferencia de la posición compacta, se encuentra fuera de la cláusula verbal.

Observemos el comportamiento del verbo maca, que es el más empleado dentro de los testamentos para la descripción de los eventos de transferencia. Este tiene un tipo de alineamiento particular según el cual el objeto que aparece indexado dentro de la palabra verbal es el $\mathrm{R}$ del evento de transferencia y no el T. Por lo tanto, los cambios de diátesis afectan al primer participante y no al 
segundo. En los casos en que el verbo aparece en su forma activa, la estrategia suele ser empleada para introducir nuevos $\mathrm{T}$ dentro de la cláusula verbal, a la vez que el A es información dada desde el inicio del documento. El R del evento, con esta construcción, usualmente, aparece dislocado a la izquierda, lo que se presenta en los ejemplos de (6).

(6) R dislocado a la izquierda en el Testamento de María Xocóyotl

6a. Auh in Tiacapan nochpoch nicnomaquilia napantli chinamitl

auh in Tiacapan no-chpoch ni-c-no-maquilia na-pantli chinamitl

CONJ DET Tiacapan.LOC 1POS-hija 1sUJ-3OBJ-1.RFLX-dar.APL cuatro-CLAS.NOM chinamitl R.DISLOC $\mathrm{T}$

'y a mi hija Tiacapan le doy cuatro chinamitl'

6b. in noconeuh Josef Lopez nicmacatiuh

in no-coneuh Josef López ni-c-maca-ti-uh chicuacempohualli pesos

DET 1POs-hijo José López 1suJ-3OBJ-dar-LIG-ir 120 pesos

R.DISLOC A.R.VBO

'a mi hijo José López le voy a dar ciento veinte pesos'

Por otra parte, cuando se topicaliza el $\mathrm{T}$-cosa que ocurre en pocas ocasiones-, debe aparecer con anterioridad como sujeto de una cláusula intransitiva; esto se debe a que el T no puede aparecer indexado en las marcas del verbo, lo que deja libre el espacio de ocurrencia de la forma léxica para el R. También puede encontrarse fuera de la cláusula a través de una dislocación tras haber sido presentado con anterioridad en el discurso; es decir, la dislocación sirve para retomar un tópico introducido con anterioridad como un S, lo que puede observarse en el ejemplo de (7).

(7) Topicalización de T en el testamento de María Xocóyotl

Auh im Mexico mani calli [...] niquincepammacatiuh in nicuhtzin ioan in Juan Aneco- $/{ }^{10}$ tzin

$\begin{array}{lllll}\text { auh } & \text { im } & \text { Mexico } & \varnothing \text {-mani } & \text { calli } \\ \text { CONJ } & \text { DET } & \text { Mexico } & \text { 3.suJ-yacer } & \text { casa.ABS } \\ \text { LOC } & & & \text { VBO } & \text { s }\end{array}$


$\mathrm{Ni-quin-cepam-maca-ti-uh} \mathrm{in} \mathrm{n}$-icuhtzin ioan in Juan Anecotazin 1SUJ-3OBJ.PL-junto-dar-LIG-ir DET 1POS-hermano.REV CONJ DET Juan Anecotzin A.R.VBO $\mathrm{R}$

'y en México yace una casa [...], se la doy enteramente a mi hermana y a Juan Anecotzin’

Dentro de los procesos de disminución de valencia nos encontramos con lo que ha sido descrito como una voz pasiva. La voz pasiva bloquea la posición de objeto, por lo que convierte a un verbo bivalente en uno monovalente. En este proceso, también es el $\mathrm{R}$ el que se vuelve sujeto de la forma pasiva, mientras que el $\mathrm{T}$ se mantiene en su posición posverbal. Launey distingue los usos pasivos de los impersonales a través de la condición de animacidad del elemento que se vuelve sujeto; así, si es un elemento inanimado, se preferirá la forma impersonal, mientras que, si es animado, se usa la pasiva. Recordemos que, para Foley (2007), los procesos de voz tienen la particularidad de bloquear la selección básica de los participantes para los rasgos que él define como [+A], [+Top] y [+Pivot], que, generalmente, suelen estar asignados al sujeto; en este caso, es el rasgo [+Top] el que se liga al argumento [-A]. En (8) tenemos un ejemplo de pasiva del verbo maca; en ellos, el sujeto se encuentra dislocado a la izquierda o se hace referencia a él a través de un predicado no verbal antes del evento de transferencia. En estos casos, el verbo aparece siempre en irrealis en la medida en que las acciones descritas se harán después de la muerte del testador. No es posible recuperar discursivamente al A del evento de transferencia.

(8) Testamento de Francisco Hernández ihoan Matheo, chane Sant Simon 'y Mateo que tiene su hogar en San Simón' $\mathrm{S}_{\mathrm{i}}$

macoz nahui pesos, $/{ }^{14}$ ihoan chicuacen tomin 'será dado con cuatro pesos y seis tomines' 
En los casos con voz pasiva, el $\mathrm{R}$ no aparece realizado léxicamente dentro de la cláusula del verbo, ya sea por su introducción como S de una cláusula anterior o a causa de la dislocación a la izquierda. Por lo tanto, la voz pasiva permite mantener las restricciones de la PAS al desarrollar al único participante restante, el T, en una colocación posverbal.

Hemos dicho, además, que el verbo maca puede aparecer con formas impersonales, que deben entenderse como formas anticausativas, en la medida que eliminan al A de la oración y mantienen exclusivamente en las marcas verbales al $\mathrm{T}$ o al $\mathrm{R}$ de la forma activa, según cuál ocupara la posición de objeto en la forma básica. Por ello, con el verbo maca, el nuevo sujeto será ocupado por el $\mathrm{R}$ del evento de transferencia. ${ }^{21}$ La mayor cantidad de ocurrencias de momaca, que es la forma impersonal del verbo maca, pospone al argumento $\mathrm{R}$, que es sujeto, y elimina completamente la referencia al antiguo A. La elección de la forma impersonal también está relacionada con la organización discursiva de los eventos, pues, en las disposiciones que se usa, se emplea la forma irrealis del verbo; es decir, son eventos que se harán una vez que el testador muera. De igual forma, discursivamente, no se ha establecido un A para esta acción. El T del evento, que otra vez se encuentra fuera de los argumentos marcados al interior de la palabra verbal, aparece topicalizado en una construcción compacta, tal como se observa en (9).

(9) Testamento de Felipe de Santa María

vI tomines momacazque teopantlaca

vi tomines $\varnothing$-mo-maca-z-que teopan-tlaca

6 tomines 3sUJ-RFLX-dar-FUT-PL iglesia.LOC-hombre.PL

T.TOP $\quad R_{i} \cdot$ VBO $\quad R_{i} \cdot S U J$

'seis tomines se le dará a los religiosos'

Como podemos observar, y a diferencia del castellano, los testamentos escritos en náhuatl mantienen las restricciones de la PAS. Esto significa que, a pesar de que en el modelo castellano de la TD se

21 Esto puede observarse con el sufijo -queh cuando el R es plural, pues este sufijo se emplea únicamente para sujetos plurales. 
encontraban pautas específicas para la elaboración discursiva (por ejemplo, presentar dos elementos nucleares realizados léxicamente y elidir verbos de transferencia), los documentos en náhuatl presentan una pauta distinta, pues, con base en los procesos de cambio de voz, puede reorganizar los participantes de un evento de transferencia para no transgredir las restricciones enunciadas por $\mathrm{Du}$ Bois.

Gracias al contraste entre ambas documentaciones, podemos observar cómo el proceso de traslado del testamento castellano al náhuatl implicó que un saber discursivo distinto del que empleaban los colonizadores se mantuviera en casos como la organización discursiva. Este no es el único punto en el que esto sucedió; podemos además mencionar el uso de posesiones predicativas no transitivas con el verbo itech pohui o con el empleo de construcciones pareadas a lo largo de los documentos. Lo contrario también es cierto: la pauta de los testamentos castellanos obligó a usos específicos que eran ajenos al náhuatl; por ejemplo, el empleo del verbo piya como un verbo de posesión transitiva o usos ditransitivos sin derivación en verbos como cabua. ${ }^{22}$ Estos nuevos usos dentro del náhuatl tienen una doble consecuencia: por una parte, el saber discursivo de los escribanos nahuas se modificó para aprender las características de este tipo de documentos que empezaron a 'manifestarse' con una lengua histórica para la que eran desconocidos. Por otra parte, estos usos permitieron que algunos cambios se introdujeran en la técnica de la lengua histórica nahua.

3. Conclusiones: la importancia del estudio de las TTDD en lenguas mesoamericanas

El punto anterior es un ejemplo de la utilidad que tiene centrarnos en las TTDD que se trasladaron a las lenguas indígenas mesoamericanas desde el enfoque que se ha generado en otras disciplinas como la romanística, pues este proceso supuso la imposición de un saber

22 Profundizamos en estos elementos en Mendoza (2018) así como en Mendoza (en prensa). 
discursivo castellano en el que el testamento tenía una funcionalidad específica - heredar los bienes - y una historia propia que data, para el español, desde la época alfonsí; las comunidades receptoras ampliaron con esto su saber discursivo a la par que modificaban las características de la tradición con el fin de conformar, con el paso del tiempo, una tradición propia a la que podemos denominar 'testamento nahua'. Gracias al análisis propuesto en las cuartillas anteriores, podemos dar cuenta de este proceso bidireccional en el que los indígenas que participaron en los foros judiciales retomaron, por necesidades pragmáticas, las características de los modelos castellanos, a la par que introdujeron en estos modelos elementos de un saber discursivo diferente, al cual podríamos llamar mesoamericano y cuyas características podemos inferir a través de estudios como el que aquí hemos presentado. Con ello, se conformó una nueva TD a la llamamos testamento nahua.

\section{Bibliografía}

\subsection{Documentos empleados}

\subsubsection{En náhuatl}

“Testamento de Ana Teacapan”. AgN, Tierras, vol. 35, exp. 6, ff. 6-7.

“Testamento de María Xocoyotl”.AgN, Tierras, vol. 35, exp. 6, f. 10.

“Testamento de Francisco Hernández Quahuicequi”. AGN, Tierras, vol. 38 , exp. 2, f. 22.

“Testamento de Martín Jacobo”. AGN, Tierras, vol. 39, 2ª parte, exp. 1, f.16. “Testamento de doña Ana de Guzmán”. AgN, Vínculos y Mayorazgos, vol. 279, exp. 1, ff. 19-21.

“Testamento de Felipe de Santa María”. Agn, Hospital de Jesús, leg. 355, exp. 13, f. 3 .

“Testamento de Juana Mocel”. AGN, Tierras, vol. 70, exp. 4, ff.13-14 “Testamento de doña Juana Cerón”. agn, Vínculos y Mayorazgos, vol. 279 , exp. 1 , ff. 27 y 29

\subsubsection{En castellano}

“Testamento de María Gómez de Engómez”. En Arias, 2014.

“Testamento de María de Espinosa”. En Arias, 2014. 


\subsection{Referencias bibliográficas}

Andrews, Avery

2007 "The major functions of the noun phrase". En Clause Structure, Language Typology and Syntactic Description. Vol. 1. Ed., Timothy Shopen. Segunda edición. Cambridge: Cambridge University Press. 132-223

Arias Álvarez, Beatriz

2014 Documentos públicos y privados del siglo XVI. Texos para la bistoria del español colonial mexicano. Colaboradores, Maribel Rosa Delgado García, Mauro Alberto Mendoza Posadas e Idanely Mora Peralta. México: UNAM.

BRIGHT, William

1990 "'With One Lip, with Two Lips': Parallelism in Nahuatl”. Language. 66. 3, 437-452. <https://doi.org/10.2307/414607>

Cline, Sara

1986 Colonial Culbuacan, 1580-1600: A Social History of an Aztec Town. Albuquerque: University of New Mexico Press.

Cline, Sara

1998 "Fray Alonso de Molina's Model Testament and Antecedents to Indigenous Wills in Spanish America”. En Dead Giveaways. Indigenous Testaments of Colonial Mesoamerica and the Andes. Eds., Susan Kellogg y Matthew Restall. Salt Lake City: University of Utah Press, 13-34.

Coseriu, Eugenio

1956 “Determinación y entorno. Dos problemas de una lingüística del hablar”. En Romanistisches Jabrbuch. VII. 29-54.

Coseriu, Eugenio

1992 Competencia lingüística. Elementos de la teoría del hablar. Elaborado y editado por Heinrich Weber. Madrid: Gredos.

Coseriu, Eugenio

2007 Lingüística del texto. Introducción a la bermenéutica del sentido. Edición, anotación y estudio previo de Óscar Lourdeda Lamas. Madrid: Arco libros. 
Du Bois, John

1987 “The Discourse Basis of Ergativity”. Language. 63. 805-855. $<$ https://doi.org/10.2307/415719>

Du BoIs, John

2003 "Argument Structure: Grammar in Use". En Preferred Argument Structure. Grammar as Architecture for Function. Eds., John W. Du Bois, Lorraine E. Kumpf y William J. Ashby. Amsterdam: John Benjamins, 224-275.

DRYER, Matthew

1986 "Primary Objects, Secondary Objects, and Antidative". Language. 62. 4, 808-845. <https://doi.org/10.2307/415173>

DrYer, Matthew

2007 "Clause Types". En Clause Structure, Language Typology and Syntactic Description. Vol. 1. Ed., Timothy Shopen. Segunda edición. Cambridge: Cambridge University Press, 132-223.

Foley, William

2007 "A Typology of Information Packing in the Clause". En Clause Structure, Language Typology and Syntactic Description. Vol. 1. Ed., Timothy Shopen. Segunda edición. Cambridge: Cambridge University Press, 362-446.

Garatea Grau, Carlos

2001 "Variedad de tradiciones discursivas en Orígenes del Español de Menéndez Pidal”. En Lengua medieval y tradiciones discursivas en la península ibérica: descripción gramatical-pragmática bistórica-metodología. Eds., Daniel Jacob y Johannes Kabatek. Madrid: Vervuert-Iberoamericana, 249-271.

Garatea Grau, Carlos

2004 "Textos, escritura y voz en la historia del español de América”. Anuario de Letras. Vol. 42. 365-376. Consultado: octubre de 2020. <https://dialnet.unirioja.es/servlet/ articulo?codigo $=2272696>$

GuZmán Riverón, Martha

2005 "Tradiciones discursivas e historia de la lengua española en América". En Cuatrocientos años de la lengua del "Quijote": estudios de historiografía e historia de la lengua española: actas de $V$ Congreso Nacional de la Asociación de Jóvenes Investi- 
gadores de Historiografía e Historia de la Lengua Española. Sevilla: Universidad de Sevilla, 79-87.

HANKs, William

2010 Converting words. Maya in the Age of the Cross. Los Angeles: University of California Press.

Hidalgo, Margarita

2006 "The Multiple Dimensions of Language Maintenance and Shift in Colonial Mexico". En Mexican Indigenous Languages at the Dawn of the Twenty-First Century. Ed., Margarita Hidalgo. Berlín: Walter de Gruyter, 53-86.

JACOB, Daniel y Johannes KaBATEK

2001 "Introducción". En Lengua medieval y tradiciones discursivas en la Península Ibérica: descripción gramatical, pragmática histórica, metodología. Eds., Daniel Jakob y Johannes Kabatek. Madrid: Iberoamericana, VII-XVIII.

KaвATEK, Johannes

2001 “Cómo investigar las tradiciones discursivas medievales? El ejemplo de los textos jurídicos castellanos”. En Lengua medieval y tradiciones discursivas en la Península Ibérica: descripción gramatical, pragmática histórica, metodología. Eds., Daniel Jakob y Johannes Kabatek. Madrid: Iberoamericana, 97-132.

KabateK, Johannes

2005 "Tradiciones discursivas y cambio lingüístico". Lexis. XXIX. 2, 151-177. Consultado: octubre de 2020. < https://www. google.com/url sa $=t \& r c t=j \& q=\&$ esrc $=s \&$ source $=w e b \& c d$ $=\& v e d=2$ ahUKEwjQ-9ioorDsAhVSd6wKHcDFDtMQFj AAegQIBBAC\&url=http $\% 3 \mathrm{~A} \% 2 \mathrm{~F} \% 2$ Frevistas.pucp.edu. pe $\% 2$ Findex.php $\% 2$ Flexis $\% 2$ Farticle $\% 2$ Fdownload $\% 2 F$ $8387 \%$ 2F8703\%2F\&usg=AOvVaw3GtchOclDXn1ePAIk zzVT5>

KABATEK, Johannes

2008 "Introducción". En Sintaxis histórica del español y cambio lingüistico. Nuevas perspectivas desde las tradiciones discursivas. Ed., Johannes Kabatek. Madrid: Iberoamericana, 7-16. 
KABATEK, Johannes

2016 "Determinación y entrono: 60 años despues". En KompetenzFunktion-Variation/Competencia-Función-Variación. Eds., Gerda Haßler y Thomas Stehl. Frankfurt am Main: Peter Lang, 19-37. Consultado: octubre de 2020. <https://www.academia. edu/25224567/Determinación_y_entorno_60_años_después>

$\mathrm{Koch}$, Peter

2008 "Tradiciones discursivas y cambio lingüístico. El ejemplo del tratamiento de Vuestra merced en español”. En Sintaxis histórica del español y cambio lingüístico. Nuevas perspectivas desde las tradiciones discursivas. Ed., Johannes Kabatek. Madrid: Iberoamericana, 53-88.

LAUney, Michel

1986 "Catégories et operations dans la grammaire nahuatl". Tesis de doctorado. Universidad de Paris IV. Consultado: octubre 2020. <http://celia.cnrs.fr/FichExt/Etudes/Launey/tm.htm>

LAUney, Michel

1992 Introducción a la lengua y a la literatura nabuatl. México: UNAM.

LOCKHART, James

1999 Los nabuas después de la Conquista: Historia social y cultural del los indios del México central, del siglo XVI al XVIII. México: Fondo de Cultura Económica.

López Serena, Araceli

2011 "La doble determinación del nivel histórico en el saber expresivo. Hacia una nueva delimitación del concepto de tradición discursiva". Romanistisches Jabrbuch. 62. 1, 59-97. Consultado: octubre de 2020. https://www.researchgate.net/ publication/270482199_La_doble_determinacion_del_nivel_ historico_en_el_saber_expresivo_Hacia_una_nueva_delimitacion_del_concepto_de_tradicion_discursiva

López Serena, Araceli

2012 "Lo universal y lo histórico en el saber expresivo: variación situacional vs. variación discursiva". Analecta Malacitana. LXXXVI. 2, 303-337. 
LOUREDA Lamas, Oscar

2007 "Presentación del editor: La Textlinguistik de Eugenio Coseriu”. En Coseriu, 2007, 19-80.

Martir Alario, María José

2011 "Los testamentos en los formularios castellanos del siglo XVI”. Tesis de doctorado. Universidad de Granada.

Martínez López-Cano, María del Pilar

1996 "Estudio intriductorio. Los inicios de la literatura notarial novohispana y la Política de Escrituras de Nicolás de Yrolo”. En La politica de escrituras. Estudio preliminar, indices, glosario y apéndices. Coord., María del Pilar Martínez LópezCano. México: unAm, IX-XXIX.

Mendoza Posadas, Mauro

2018 "Tradiciones Discursivas bilingües en la Colonia. El caso del testamento nahua”. Tesis de maestría. Universidad Nacional Autónoma de México.

Mendoza Posadas, Mauro

Prensa "Un caso de extensión semántica en testamentos nahuas coloniales. Un análisis desde las Tradiciones Discursivas”. En Memorias del Taller de los Amigos de las Lenguas Yutoaztecas 2019. Homenaje a Karen Dakin. Guadalajara: Universidad de Guadalajara.

Mentz, Brigida von

2008 Cuaubnábuac 1450-1675. Su bistoria indígena y sus documentos en mexicano. México: Miguel Ángel Porrúa.

Mijares Ramírez, Ivonne

1997 Escribanos y escrituras públicas en el siglo XVI. El caso de la ciudad de México. México: UNAM.

Molina, fray Alonso de

[1569] 1984 Confesionario mayor en la lengua mexicana y castellana. Introducción de Roberto Moreno. Quinta edición facsimilar. México: UnAM.

MonTes de Oca, Mercedes

2017 "El náhuatl de escribanía, hacia su caracterización como registro”. En Lenguas en contacto, procesos de nivelación y 
lugares de escritura. Variación y contextos de uso. Guadalajara: Universidad de Guadalajara, 41-164.

Oesterreicher, Wulf

2001 "La 'recontextualización' de los géneros medievales como tarea hermenéutica”. En Lengua medieval y tradiciones discursivas en la Península Ibérica: descripción gramatical, pragmática histórica, metodología. Eds., Daniel Jakob y Johannes Kabatek. Madrid: Iberoamericana, 199-231.

Peralta, Valentín et al.

2004 "Traducción de documentos de náhuatl. Una perspectiva interdisciplinaria”. Estudios de cultura Nábuatl. 35. 179-206.

Paoli, Antonio

1989 La lingüistica en Gramsci. Teoría de la comunicación política. Puebla: Premia.

Perna, Caros Gabriel

2014 "En torno a la teoría de los entornos de Eugenio Coseriu. El caso de la «región»". Revista argentina de historiografía lingüistica. VI. 2, 143-160.

RENWIK, Ricardo

1997 "El proyecto de investigación: escritura de impronta oral en la historiografía colonial de Hispanoamérica: 1500 a 1615: Fundamentos teóricos y metodología”. Lexis. 21. 1, 17-52. Consultado: octubre de 2020. <http://revistas.pucp.edu.pe/ index.php/lexis/article/view/7391>

Reyes García, Luis

$2001 \quad ¿$ Cómo te confundes? ¿Acaso no fuimos conquistados? Anales de Juan Bautista. México: CIESAs-Biblioteca Lorenzo Boturini.

RojAs, Rabiela, Teresa et al.

1999 Vidas y vienes olvidados. Testamentos indígenas novohispanos. México: CIESAS.

STEger, Hugo

1972 "Redekonstellation, Redekonstellationstyp, Textexemplar, Textsorte im rahmen eines Sprachverhaltensmodells". Gesprochene Sprache. Sprache der Gegewart. 26. 39-97. 
Schlieben-Lange, Brigitte

1983 Traditionen des Sprechens. Elemente einer pragmatischen Sprachgeschichtsschreibung. Stuttgart: Kohlhammer.

Schlieben-Lange, Brigitte

1987 Pragmática lingüística. Madrid: Gredos.

Steger, Hugo et al.

1972 "Redekonstellation, Redekonstellationstyp, Textexemplar, Textsorte im Rahmen eines Sprachverhaltensmodells". Gesprochene Sprachen (Sprache der Gegenwart). 26, 39-97.

Tuggy, David

1997 "Giving in Nawatl". En The Linguistics of Giving. Ed., John Newman. Amsterdam: John Benjamins, 35-65.

WiCHMANN, Søren

2004 The Linguistics of Mayan Writing. Salt Lake City: The University of Utah Press. 